06

\title{
Исследование массотранспортных потерь структурно-модифицированных электродов воздушно-водородных топливных элементов методом вольт-амперной характеристики
}

\author{
() Н.В. Глебова, А.О. Краснова, А.А. Нечитайлов, А.А. Томасов, Н.К. Зеленина \\ Физико-технический институт им. А.Ф. Иофрфе РАН, \\ 194021 Санкт-Петербург, Россия \\ e-mail: glebova@mail.ioffe.ru
}

Поступило в Редакцию 6 августа 2020 г.

В окончательной редакции 13 ноября 2020 г.

Принято к публикации 14 ноября 2020 г.

\begin{abstract}
Рассмотрены платино-углеродные электроды со смешанной проводимостью в составе мембранноэлектродных блоков топливных элементов, содержащих структурно-модифицирующие добавки со структурными элементами различного типа: углеродные нанотрубки, имеющие вытянутые структурные элементы, и графеноподобные материалы с практически двумерными плоскостями. На основании данных о предельной плотности тока, полученной в потенциодинамическом и потенциостатическом режимах, исследованы массотранспортные потери переноса молекулярного кислорода в этих электродах. При использовании различных условий измерения построены барические зависимости плотности тока, выяснены лимитирующие факторы и механизмы переноса кислорода в исследованных структурах и роль вводимых модификаторов.
\end{abstract}

Ключевые слова: платино-углеродные электроды, массоперенос, мембранно-электродные блоки, Nafion.

DOI: 10.21883/JTF.2021.04.50626.241-20

\section{Введение}

Массоперенос играет существенную роль в функционировании электрохимического электрода топливного элемента, поскольку является одной из стадий электрохимического процесса, включающего подвод вещества к поверхности электрода, перенос вещества внутри пористого электрода к поверхности электрокатализатора, адсорбцию на поверхности электрокатализатора, реакцию разряда на поверхности и перенос зарядов. Каждый процесс связан с определенными энергетическими потерями и имеет свои кинетические характеристики, которые в свою очередь зависят от многих факторов. В конечном счете в соответствии с положениями электрохимической кинетики скорость общего многостадийного процесса лимитируется скоростью наиболее медленной его стадии. Таким образом, наиболее эффективно функционирующее устройство должно иметь близкие скорости отдельных процессов.

Сложность и многостадийность электрохимических процессов в мембранно-электродных блоках (МЭБ) обусловливает трудности в их раздельном изучении. В то же время, как хорошо известно, массотранспортные потери в пористых средах являются одними из существенных потерь, поэтому фундаментальные и прикладные исследования, направленные на их уменьшение - одно из актуальных направлений в области изучения топливных элементов.

Управление структурой пористой среды с целью снижения массотранспортных потерь - довольно распространенный прием в мировой практике [1-3]. Так, в [1,2] посредством математического моделирования исследовано влияние структуры на транспортные свойства. В [1] исследовано диффузионное и электрическое сопротивление, механическая прочность, показано, что структура типа решетки характеризуется сочетанием высокой скорости переноса вещества при относительно низком электрическом сопротивлении, и при этом обладает механической устойчивостью и обеспечивает сплошность электропроводящей среды. В [2] предложена модель для характеристики нелинейной зависимости механического напряжения от деформации структуры углеродной бумаги, используемой в качестве газодиффузионного слоя, при сжимающей нагрузке. Показано, что модель может быть использована при моделировании структур, модифицированных добавками политетрафторэтилена. В экспериментальной работе [3] исследована возможность замены газодиффузионной среды из углеродного волокна на композит из углеродной сажи и политетрафторэтилена. Приведены исследования влияния пористой структуры на эффективность использования катализатора методом циклической вольтамперометрии. Показано, что монолитные слои с порами достигают на $27 \%$ большей плотности мощности по сравнению со стандартными.

Углеродные наноструктурированные материалы как модификаторы структуры электродов представляют особый интерес [4-6], поскольку обладают широким набором форм отдельных элементов (нанотрубки, графены, сажа и т.д.). Некоторые из них были успешно использованы нами для модифицирования пористой структуры [7]. В [4] использованы углеродные нано- 
трубки (УНТ) в качестве добавки, увеличивающей пористость, и политетрафторэтилен для модулирования поверхности. Показано, что УНТ не только увеличивают пористость электрода, но и повышают эффективность использования платинового катализатора. В [5] обобщено использование УНТ в топливных элементах, показано, что благодаря УНТ можно снизить содержание благородных металлов в каталитическом слое и улучшить характеристики топливных элементов. В [6] представлен обзор использования наноструктур в технологии топливных элементов с особым акцентом на нанокатализаторы. Проанализирована роль наноструктур в снижении себестоимости топливных элементов. Отмечено негативное влияние некоторых наноматериалов на экологию.

Таким образом, исследование роли структурного фактора в эффективности топливных элементов является актуальным, и при этом анализ публикаций по этой тематике показывает недостаточную на данный момент разработанность этого научного направления.

Цель настоящей работы состоит в исследовании массотранспортных потерь переноса молекулярного кислорода в платино-углеродных электродах со смешанной проводимостью в составе МЭБ, содержащих структурномодифицирующие добавки со структурными элементами различного типа: УНТ, имеющие вытянутые структурные элементы, и графеноподобные материалы с практически двумерными плоскостями.

\section{1. Эксперимент}

В настоящей работе посредством регистрации вольт-амперных характеристик (BAX) и тока короткого замыкания в потенциодинамическом и потенциостатическом режимах соответственно исследована предельная плотность тока различных МЭБ. В данном случае предельная плотность тока может зависеть от степени затопления пор водой, но в то же время образец должен быть полностью увлажнен для обеспечения протонной проводимости. Для обеспечения по возможности близких условий и для минимизации изменения свойств МЭБ в процессе измерений после его активации использовали динамический режим регистрации $\mathrm{BAX}$ при скорости поляризации $10 \mathrm{mV} / \mathrm{s}$. В таком режиме (время измерения $100 \mathrm{~s}$ ) обычно не происходило значимого изменения состояния пористого электрода в процессе регистрации ВАХ, что следует из воспроизводимости BAX (в пределах 10\% относительных) при прямом и обратном направлении поляризации. Влияние тока заряжения двойного электрического слоя при такой скорости поляризации несущественно. Численные оценки показывают, что при массе электрода $1 \mathrm{mg}$ и удельной площади поверхности материала $250 \mathrm{~m}^{2} / \mathrm{g}$, поляризационной емкости $20 \mu \mathrm{F} / \mathrm{cm}^{2}$ при скорости поляризации $10 \mathrm{mV} / \mathrm{s}$ плотность тока заряжения двойного электрического слоя (ДЭС) составит $0.5 \mathrm{~mA}$.
Другие факторы, влияющие на экспериментальные данные, выявляли путем сопоставления результатов, полученных при использовании методов ВАХ и тока короткого замыкания. Ряд измерений проводили при различных давлениях газов.

\section{1. Использованные материалы}

При изготовлении МЭБ использовали композитные электродные материалы, содержащие платинированную углеродную сажу, модифицирующие структурные добавки: многостенные УНТ и графеноподобный материал, протонпроводящий полимер типа Nafion.

\subsection{1. Платинированная углеродная сажа (Pt/C)}

Использовали коммерческий продукт под маркой E-TEK, содержащий 40\% платины на углеродной саже типа Vulcan XC-72 [8]. Удельная площадь поверхности составляет $200[9]-250 \mathrm{~m}^{2} / \mathrm{g}$ [10-13].

\subsection{2. $\quad \mathrm{YHT}$}

Использовали многостенные УНТ типа Таунит МД (производство ООО „НаноТехЦентр“, Тамбов) [14].

Характерными структурными свойствами этих нанотрубок являются большое отношение длины к диаметру, составляющее 670-2500 (рис. 1), и высокая пористость за счет пор больше $100 \mathrm{~nm}$ [15]. УНТ были очищены от примесей катализаторов, используемых при их получении, посредством кислотной обработки, промывки дистиллированной водой и сушки. В качестве кислоты использовали азотную кислоту, разбавленную водой в объемном отношении $1: 1$. Обработку вели при температуре около $100^{\circ} \mathrm{C}$ в течение $\sim 15 \mathrm{~min}$. Была выбрана азотная кислота, так как она наиболее полно растворяет примеси (установлено опытным путем).

Характеристики используемых УНТ представлены в табл. 1. Наличие в материале значительного количества кислорода связано с его присоединением в процессе кислотной обработки в окислительной среде.

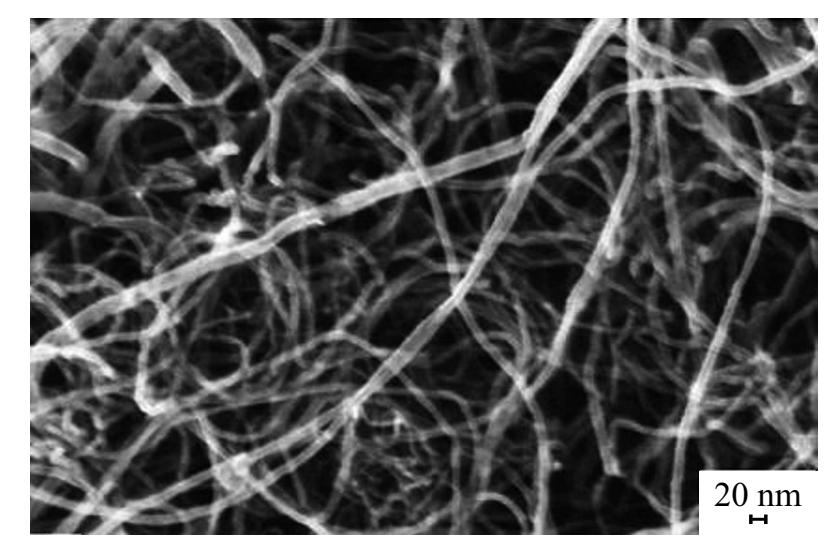

Рис. 1. СЭМ изображение многостенных УНТ типа Таунит МД. 
Таблица 1. Структурные характеристики (данные производителя [14]) и элементный состав [15] УНТ типа Таунит МД

\begin{tabular}{l|c|c|c}
\hline \multicolumn{1}{c|}{ Параметр } & Значение & Элемент & Содержание, таss. \\
\hline Внешний диаметр, $\mathrm{nm}$ & $8-30$ & $\mathrm{C}$ & 96.1 \\
Внутренний диаметр, $\mathrm{nm}$ & $5-15$ & $\mathrm{O}$ & 3.86 \\
Длина, $\mu \mathrm{m}$ & $\geq 20$ & - & - \\
Насыпная плотность, $\mathrm{g} / \mathrm{cm}^{3}$ & $0.025-0.06$ & - & - \\
Удельная поверхность, $\mathrm{m}^{2} / \mathrm{g}$ & $\geq 270$ & - &
\end{tabular}

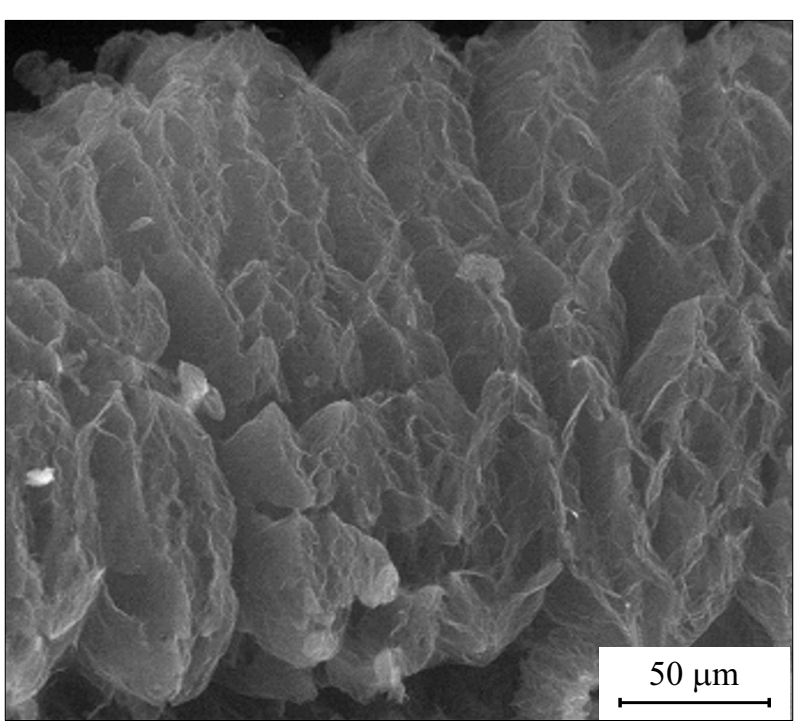

Рис. 2. Микрофотография исходного порошка терморасширенного графита.

\subsection{3. Графеноподобный материал на основе терморасширенного графита}

Терморасширенный графит (ТРГ) использовали в форме порошка, структура которого показана на рис. 2. В качестве ТРГ использовали углеродный материал [16]. Как видно из рисунка, материал имеет структуру сросшихся пластин. Исходный материал аттестовали по структурным характеристикам и элементному составу. Данные исследования исходного ТРГ методами адсорбционной спектроскопии (низкотемпературная адсорбция азота) и рентгеновской электронной спектроскопией приведены в табл. 2.

Исходя из анализа типа изотермы адсорбции азота (II тип) и типа петли гистерезиса (Н3), следует, что материал имеет щелевидные поры, ограниченные плоскопараллельными структурными элементами. Наличие примесей галогенов и кислорода связано с технологией ТРГ. Интервал содержаний того или иного элемента связан с анализом различных областей поверхности образца. В процессе приготовления электродного материала (включает ультразвуковую обработку, см. ниже), и электрохимического воздействия (активирование, функционирование МЭБ) происходило расщепление ТРГ на пластины [17].

\subsection{4. Протонпроводящий полимер типа Nafion}

Для введения иономера в электродный материал использовали коммерческий продукт Ion Power Inc. DUPONT DE2020 - водно-пропанольный раствор Nafion концентрации $20 \%$.

Мембранно-электродные блоки изготавливали на протонпроводящей мембране типа МФ4-СК производства ОАО „Пластполимер“.

\section{2. Образцы}

Для исследования изготавливали образцы МЭБ. Исходным электродным материалом для этих образцов служили дисперсии твердых компонентов в водноспиртовой среде соответствующего компонентного состава.

\section{3. Приготовление дисперсии}

Технологические операции приготовления дисперсии электродного материала включали две стадии: механическое и ультразвуковое диспергирование смеси точных навесок компонентов в смеси и-пропанол-вода. Объемное соотношение жидких составляющих и-пропанолвода находилось в диапазоне $1: 1-1: 5$. Отношение

Таблица 2. Структурные характеристики и элементный состав терморасширенного графита

\begin{tabular}{c|c|c|c}
\hline Параметр & Значение & Элемент & Содержание, таss. \\
\hline Насыпная плотность, $\mathrm{g} / \mathrm{cm}^{3}$ & 0.002 & $\mathrm{C}$ & $91.1-92.8$ \\
Удельная площадь поверхности (по БЭТ), $\mathrm{m}^{2} / \mathrm{g}$ & 143 & $\mathrm{I}$ & $2.62-3.18$ \\
- & - & $\mathrm{O}$ & $3.01-1.81$ \\
& - & $\mathrm{Br}$ & $0.23-0.48$
\end{tabular}


твердой фазы к жидкой в конечной дисперсии при этом находилось в диапазоне $1: 40-1: 80$. Формирование части электродов проводили способом, предусматривающим предварительное коагулирование Nafion из его раствора в жидкой фазе с последующим введением в структуру электрода $[15,18]$. Для этого коммерческий раствор Nafion в заданной концентрации перед добавлением в дисперсию разбавляли водой в объемном отношении $1: 1$.

Механическое диспергирование выполняли на магнитной мешалке типа Milaform MM-5M со скоростью вращения якоря $\sim 400$ оборотов в минуту с изолированным в пластиковый кожух якорем до визуально однородной (без видимых комочков) массы $(\sim 0.5 \mathrm{~h})$. Последующее ультразвуковое диспергирование проводили в ультразвуковой ванне типа Branson 3510 в течение 40-100 h до получения однородной, не расслаивающейся в течение минуты, дисперсии.

\section{4. Изготовление МЭБ}

МЭБ были изготовлены путем нанесения однородной дисперсии компонентов непосредственно на протонпроводящую мембрану через маску из нержавеющей стали. Перед нанесением электродного материала мембрану выдерживали в $0.5 \mathrm{M}$ серной кислоте в течение $15 \mathrm{~min}$ при температуре $70-80^{\circ} \mathrm{C}$ с последующей пятикратной промывкой водой. Электроды изготавливали путем нанесения дисперсии компонентов в смеси изопропанолвода на протонпроводящую мембрану типа Nafion (марка МФ4-СК) толщиной $50 \mu \mathrm{m}$. Мембрану термостатировали при $85^{\circ} \mathrm{C}$ на плитке типа Ika C-MAGHP 7 c терморегулятором. Количество нанесенного материала контролировали гравиметрически.

Перед проведением электрохимических измерений МЭБ с целью протонирования Nafion выдерживали в $0.5 \mathrm{M}$ серной кислоте в течение $15 \mathrm{~min}$ при температуре $70-80^{\circ} \mathrm{C}$ с последующей пятикратной промывкой водой.

\section{5. Методика измерений}

МЭБ предварительно активировали методом, описанным в [19]. При проведении электрохимических измерений МЭБ помещали в стандартную двухэлектродную электрохимическую ячейку (FC-05-02) [20]. BAX и ток короткого замыкания (КЗ) регистрировали с использованием потенциостата типа Р-150 (производство ООО „Элинс“", Черноголовка) в среде влажных (насыщенных парами воды) газов $\mathrm{O}_{2} / \mathrm{H}_{2}$. Годографы электрохимического импеданса регистрировали на приборе импедансметр Z500P + AX500PL (производство ООО „Элинс“, Черноголовка). Схема измерения представлена на рис. 3.

На катодное и анодное пространство подавали соответствующие насыщенные водой реакционные газы (кислород и водород), приведенные к необходимым условиям - температуре, давлению, потоку. Насыщение

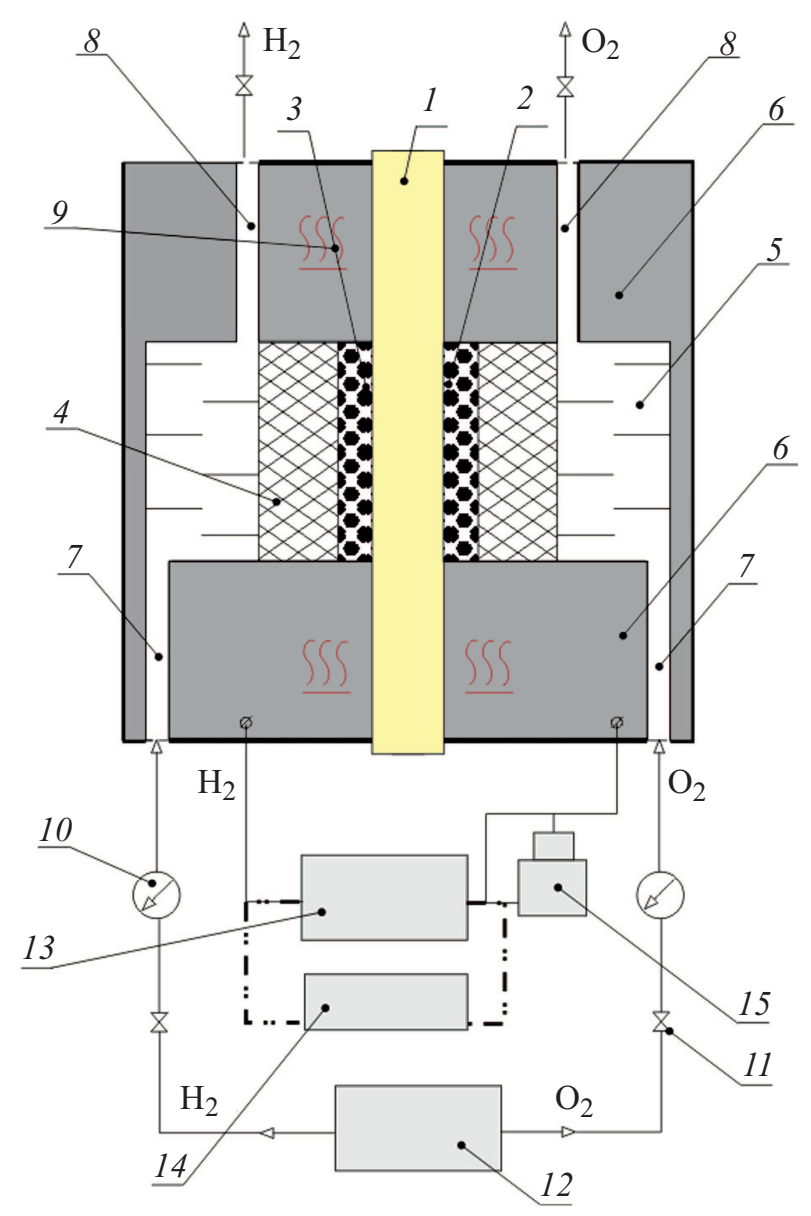

Рис. 3. Схема измерения электрохимических характеристик МЭБ: 1 - протонпроводящая мембрана, 2 - катод, 3 - анод, 4 - газодиффузионные слои, 5 - газоподводящие каналы, 6 - контактная (токосъемная) пластина, 7 - газоподводящие отверстия, 8 - газоотводящие отверстия, 9 - регулируемые нагреватели, 10 - газовые редукторы, 11 - газовые вентили, 12 - электролизер, 13 - потенциостат, 14 - импедансметр, 15 - управляющий компьютер.

водой проводили путем барботирования через дистиллированную воду при температуре эксперимента.

Измерения проводили в различных режимах:

1) регистрирование ВАХ в потенциодинамическом режиме;

2) регистрирование тока короткого замыкания в потенциостатическом режиме;

3) регистрирование годографа электрохимического импеданса при напряжениях, близких к напряжению разомкнутой цепи.

\section{2. Вычисления}

\section{1. Вычисление пористости}

Толщину электродов измеряли толщиномером с разрешением $0.5 \mu \mathrm{m}$ в 10 точках слоя. За результирующее значение толщины принимали среднее арифметическое. 


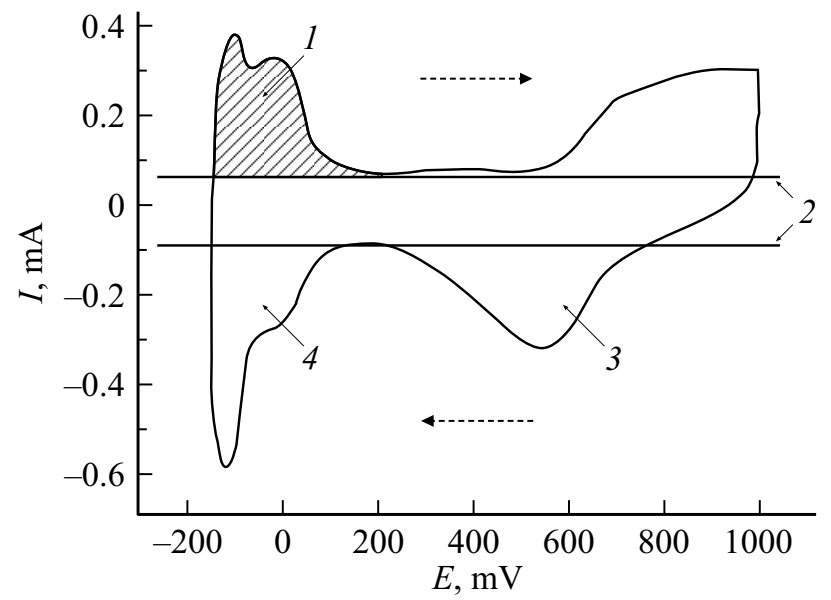

Рис. 4. Характерная циклическая вольтамперограмма: 1 - область десорбции водорода, 2 - горизонтальные линии, соответствующие току заряжения ДЭС, 3 - область десорбции кислорода, 4 - область адсорбции водорода. Пунктирными стрелками показано направление изменения потенциала.

Площадь электродов составляла $1 \mathrm{~cm}^{2}$. Пористость электродов вычисляли исходя из известного компонентного состава, толщины и площади по соотношению

$$
P=1-\frac{\sum_{i=1}^{n}\left(\left(\omega_{i} \cdot G\right) / d_{i}\right)}{V},
$$

где $P$ - пористость (объемная доля пор) электрода, $V$ - объем электрода (в данном случае при длине и ширине электрода по $1 \mathrm{~cm}$ объем численно равен толщине), $\omega_{i}-$ массовая доля $i$-го компонента, $G-$ масса электрода, $d_{i}$ - плотность $i$-го компонента.

\section{2. Коррекция электродного потенциала}

Для коррекции потенциала использовали электрическое сопротивление измерительной цепи $R$, полученное по высокочастотной отсечке годографа электрохимического импеданса на оси реальных сопротивлений. По полученным данным делали поправку (вычисляли $E_{\text {correction }}-$ потенциал с учетом поправки) $E$ для каждого текущего значения тока $I$ для экспериментальных полярограмм по соотношению:

$$
E_{\text {correction }}=E+I \cdot R \text {. }
$$

\section{3. Вычисление электрохимически активной площади пористого электрода}

Использовали известное положение: поляризационная емкость $C_{P}=16-20 \mu \mathrm{F} / \mathrm{cm}^{2}$ [21,22]. В соответствии с этим площадь $S$ вычисляли исходя из скорости поляризации $v$ и тока заряжения ДЭС $-I$, по соотношению

$$
S=I /\left(v \cdot C_{p}\right) .
$$

\section{4. Вычисление электрохимически активной площади поверхности платины}

Электрохимически активную площадь поверхности платины $\mathrm{S}_{\mathrm{Pt}}$ вычисляли по заряду, соответствующему электрохимической десорбции водорода в водородной области циклической вольтамперограммы. Для этого путем численного интегрирования вычисляли заряд, пошедший на десорбцию водорода (см. схему на рис. 4). Интегрировали область токов $I(1)$ в интервале потенциалов $E 1-E 2$, соответствующем десорбции водорода, ограниченную сверху кривой циклической вольтамперометрии (ЦВА-кривой) и снизу - горизонтальной линией (для исключения заряда, соответствующего заряжению двойного электрического слоя). Заряд, потраченный на десорбцию водорода, делили на коэффициент, соответствующий заряду водорода, десорбированному с единицы площади поверхности платины $\left(210 \mu \mathrm{C} / \mathrm{cm}^{2}\right)[23]$.
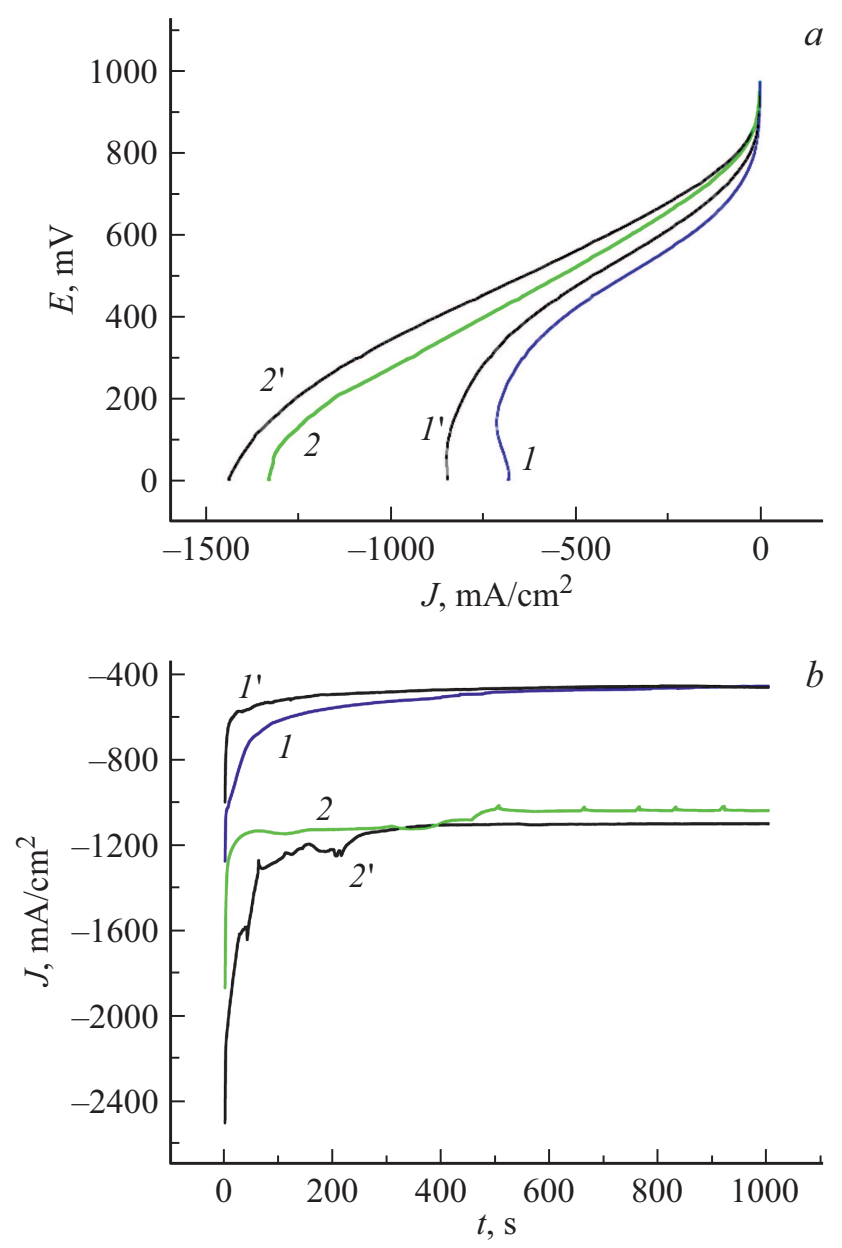

Рис. 5. Вольт-амперные $(a)$, скорость поляризации $10 \mathrm{mV} / \mathrm{s}$, и потенциостатические $(b)$, режим КЗ, характеристики МЭБ образца $\mathrm{Pt} / \mathrm{C}+\mathrm{УHT}$ Таунит МД + Nafion. 1, $1^{\prime}$ - воздух/водород (водород/воздух); 2, 2' - кислород/водород (водород/кислород) соответственно, газы насыщены парами воды, температура $\sim 25^{\circ} \mathrm{C}$. 

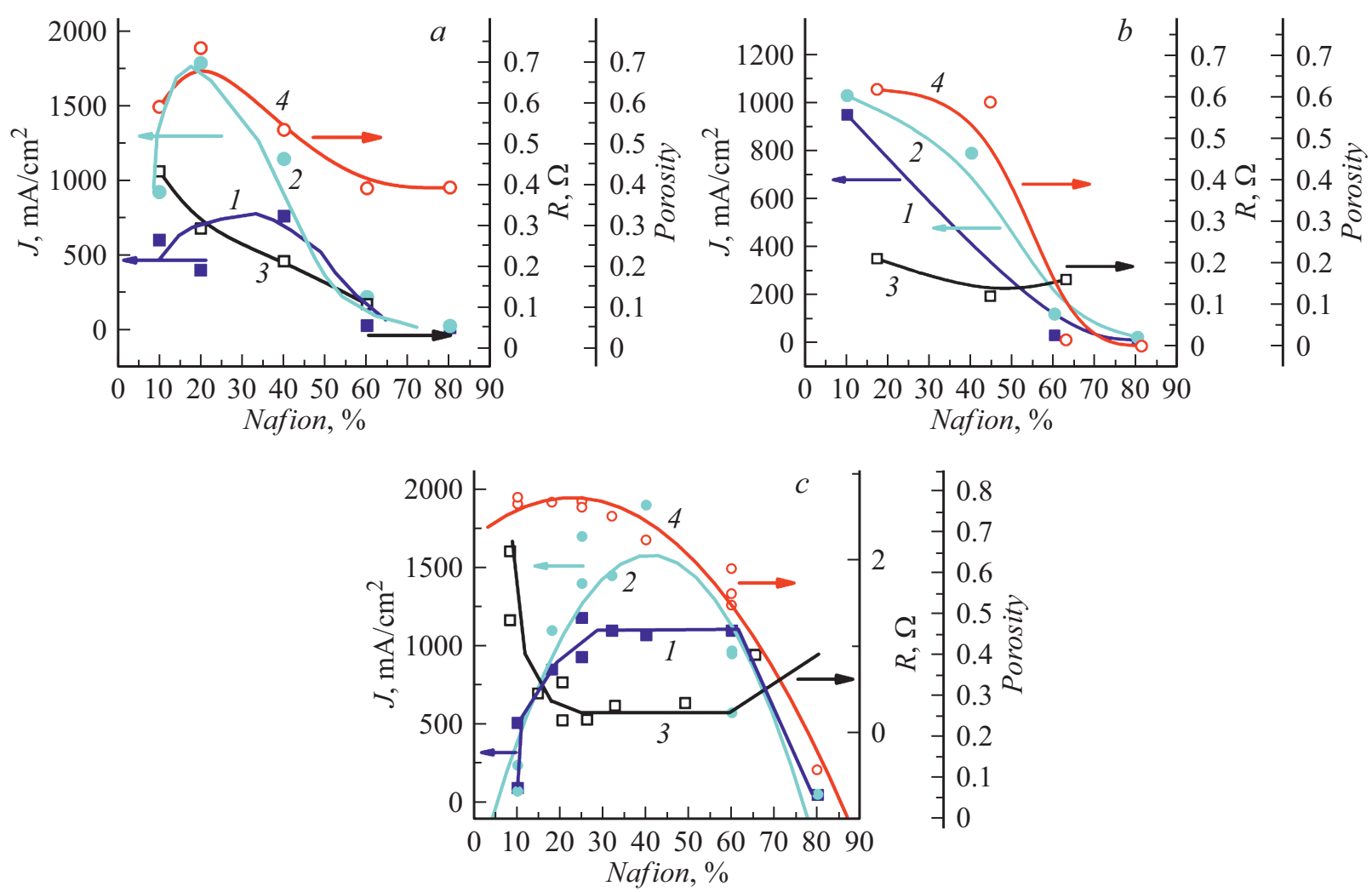

Рис. 6. Плотности предельных токов мембранно-электродных блоков в зависимости от содержания Nafion с электродами различного состава: $a-$ E-TEK + Nafion; $b-$ E-TEK + ТPГ + Nafion; $c-$ E-TEK + Таунит MД + Nafion; $1-J_{\text {shortcircuit }}$ (потенциостатический режим), $2-J_{\text {shortcircuit }}(\mathrm{BAX}), 3-R_{\text {ion }}$, катод, импеданс, $4-$ пористость.

\section{3. Результаты измерений}

С целью выяснения влияния скорости поляризации на результаты измерения площади поверхности платины проводили измерения при различных скоростях поляризации в диапазоне $10-1000 \mathrm{mV} / \mathrm{s}$. При этом, по крайней мере при скорости от 30 до $100 \mathrm{mV} / \mathrm{s}$, измеряемая площадь поверхности имела постоянное значение в пределах 10\% (относительных) для толщины слоя до $\sim 40 \mu \mathrm{m}$.

На рис. 5 приведены характерные потенциодинамические $(\mathrm{BAX})$ и потенциостатические характеристики МЭБ образца $\mathrm{Pt} / \mathrm{C}+\mathrm{УHT} \mathrm{Таунит} \mathrm{МД+Nafion.}$

Из рисунков видно, что величины предельных плотностей тока различаются как для различных газовых сред, так и для различных режимов регистрации этих зависимостей. В случае использования кислорода в качестве окислителя предельные плотности тока в 1.7 и 2.4 раза больше, чем в случае воздуха для режимов ВАХ и потенциостатического соответственно. Различие в предельных плотностях тока для кислорода и воздуха хорошо известное явление, связанное с различной концентрацией кислорода. Различие предельных плотностей тока для различных режимов измерения можно объяснить тем, что в случае потенциостатического режима в большей степени происходит затопление пор водой.
Действительно, из рис. $5, b$ видно, что стационарное состояние устанавливается в первые десятки секунд. В дальнейшем происходит стабилизация плотности тока.

На рис. 6 представлены зависимости предельной плотности тока, ионного сопротивления катода и пористости от содержания Nafion для МЭБ с электродами различного состава. При этом приведены данные для предельной плотности тока, измеренной в режиме ВАХ в потенциостатическом режиме.

Общим для всех структур является то, что плотности тока, измеренные в потенциостатическом режиме, меньше соответствующих плотностей тока, измеренных в потенциодинамическом режиме для каждого образца. Это, как сказано выше, связано с различной степенью заполнения пор водой.

Из рисунков следует, что для образцов, не содержащих добавок (только E-TEK и Nafion), и для образцов, содержащих добавку ТРГ (рис. 6, $a, b$ ), кривые плотностей тока по существу симбатны кривым пористости и в меньшей степени коррелируют с кривыми сопротивления, тогда как для образцов с УНТ (рис. 6,c) хорошо прослеживается корреляция с сопротивлением. Последнее обстоятельство можно объяснить особенностями структуры электродов, содержащих УНТ [7].

В таких электродах Nafion пространственно сильно рассогласован с платиной. Это приводит к относительно 
Таблица 3. Зависимость плотности тока короткого замыкания от давления

\begin{tabular}{|c|c|c|c|c|c|c|}
\hline \multirow[b]{2}{*}{ Состав } & \multirow[b]{2}{*}{$\mathrm{GPt}, \mathrm{mg}$} & \multirow{2}{*}{$\begin{array}{c}\mathrm{SPt} \\
\text { (на электродах), } \\
\mathrm{cm}^{2}\end{array}$} & \multirow{2}{*}{$\begin{array}{c}\text { Пористость } \\
\text { электрода, } \\
\text { \% }\end{array}$} & \multicolumn{2}{|c|}{$\mathrm{J}=\mathrm{A}+\mathrm{B} * \mathrm{P}$} & \multirow{2}{*}{$\begin{array}{c}\text { Коэффициент } \\
\text { корреляции } \\
R\end{array}$} \\
\hline & & & & $\begin{array}{c}\mathrm{A}, \\
\mathrm{mA} / \mathrm{cm}^{2}\end{array}$ & $\begin{array}{c}\mathrm{B}, \\
\mathrm{mA} /\left(\mathrm{cm}^{2} \cdot \operatorname{atm}\right)\end{array}$ & \\
\hline Pt/C + нескоагулированный 20\% Nafion & $0.1 / 0.09$ & $45.3 / 47.9$ & 50.5 & 988 & 49.2 & 0.46571 \\
\hline $\mathrm{Pt} / \mathrm{C}+10 \%$ Nafion & $0.08 / 0.1$ & $15.2 / 37.0$ & 62.3 & 539 & 107 & 0.87425 \\
\hline $\mathrm{Pt} / \mathrm{C}+80 \%$ Nafion & $0.1 / 0.1$ & $31.6 / 22.6$ & 39.0 & 12.4 & 4.11 & 0.97201 \\
\hline $\mathrm{Pt} / \mathrm{C}+45 \%$ ТРГ $+10 \%$ Nafion & $0.1 / 0.06$ & $33.0 / 37.4$ & 61.7 & 991.2 & 195.9 & 0.99431 \\
\hline $\mathrm{Pt} / \mathrm{C}+20 \%$ ТРГ $+60 \%$ Nafion & $0.19 / 0.1$ & $16.6 / 11.0$ & 10.4 & 110 & 26.8 & 0.86413 \\
\hline $\mathrm{Pt} / \mathrm{C}+34 \%$ УНТ Таунит МД $+32 \%$ Nafion & $0.17 / 0.12$ & $109 / 121$ & 73.8 & 1470 & 33.8 & 0.5239 \\
\hline
\end{tabular}

Примечание. Условия: влажные водород/кислород, $T=22-25^{\circ} \mathrm{C}$, скорость поляризации $10 \mathrm{mV} / \mathrm{s}$.

более высокому сопротивлению переносу протонов и, наоборот, к уменьшению эффективного диффузионного сопротивления переносу молекулярного кислорода к поверхности платины. Таким образом, если в случае электродов без добавок и с добавкой ТРГ плотность тока лимитируется пористостью, то в случае электродов с УНТ лимитирующим фактором становится ионное сопротивление, имеющее относительно небольшую величину. Такая зависимость предпочтительна для рабочих режимов топливных элементов, так как в большинстве случаев их работоспособность ограничивает не протонное, а газотранспортное диффузионное сопротивление.

На рис. 7 показаны зависимости предельного тока, измеренного методом ВАХ, от давления для образцов различного состава.

Анализ экспериментальных зависимостей (рис. 7) показывает, что точки хорошо аппроксимируются прямыми с различным положительным наклоном. Это свидетельствует о протекании диффузии кислорода к поверхности платины не в свободномолекулярном режиме (см. выше). Поскольку плотность тока все же зависит от давления и увеличивается с его возрастанием в то время как ряд образцов имеет поры размером, превышающим длину свободного пробега молекулы кислорода в газе [7], можно утверждать, что в диффузию кислорода существенный вклад вносит диффузия через пленку Nafion. В табл. 3 приведены характеристики исследованных образцов и численные значения коэффициентов в выражениях прямых, описывающих зависимости плотности предельного тока от давления.

Наибольшие значения плотности тока, как следует из рис. 7 и табл. 3, характерны для образцов с УНТ, что согласуется с представлениями об особенностях структурообразования (см. выше). Для образцов с УНТ наблюдается наиболее широкий интервал содержаний Nafion (25-60\%), в котором предельная плотность тока имеет высокое значение на уровне более $1000 \mathrm{~mA} / \mathrm{cm}^{2}$ как для потенциодинамического, так и для потенциостатического режимов. Для образцов без добавок плотность предельного тока при потенциостатическом режиме не превышает $760 \mathrm{~mA} / \mathrm{cm}^{2}$, а для потенциодинамического режима интервал, в котором образцы демонстриру-

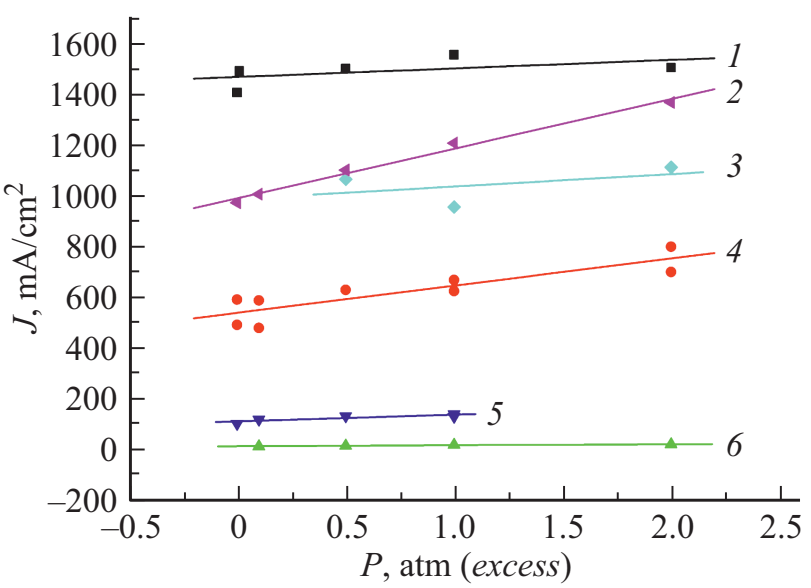

Рис. 7. Барические зависимости плотности тока КЗ МЭБ с электродами различного состава: $1-\mathrm{Pt} / \mathrm{C}+34 \%$ УНТ Таунит МД $+32 \%$ Nafion, $2-\mathrm{Pt} / \mathrm{C}+45 \%$ ТРГ $+10 \%$ Nafion, $3-\mathrm{Pt} / \mathrm{C}+20 \%$ Nafion, $4-\mathrm{Pt} / \mathrm{C}+10 \%$ Nafion, $5-$ $\mathrm{Pt} / \mathrm{C}+20 \%$ TPГ $+60 \%$ Nafion, $6-\mathrm{Pt} / \mathrm{C}+80 \%$ Nafion. Раствор Nafion во всех образцах, кроме № 3, предварительно скоагулирован.

ют плотность предельного тока выше $1000 \mathrm{~mA} / \mathrm{cm}^{2}$, уже: $10-40 \%$ Nafion. Это свидетельствует о большей чувствительности электродов традиционного состава к затоплению водой. Образцы с ТРГ демонстрируют самые низкие значения плотностей предельного тока, не превышающие $1000 \mathrm{~mA} / \mathrm{cm}^{2}$, на всем интервале составов. При этом плотности тока, измеренные в различных режимах, у них наиболее близкие.

\section{4. Обсуждение результатов экспериментов}

1.Для всех образцов предельная плотность тока в случае потенциостатического режима меньше, чем для потенциодинамического режима, при этом зависимости плотности тока от состава симбатны; это объясняется большим заполнением пор водой в последнем случае.

2. Зависимости предельной плотности тока от содержания Nafion для традиционных электродов и электро- 
дов, модифицированных ТРГ, симбатны кривой пористости, в то время как для электродов, модифицированных УНТ, плотность предельного тока лимитирована ионным сопротивлением; это связано с особенностями структуры электродов с УНТ, где Nafion и платина рассогласованы в пространстве, в результате этого диффузионное сопротивление переносу молекулярного кислорода к поверхности платины перестает лимитировать общий электрохимический процесс, а ионное сопротивление увеличено.

3. Барические зависимости предельного тока для всех электродов имеют положительную производную, что свидетельствует о наличии лимитирующей стадии процесса переноса молекулярного кислорода к поверхности платины через пленку Nafion.

\section{Выводы и рекомендации}

МЭБ с электродами, модифицированными УНТ, обеспечивают самые высокие плотности предельных токов в широком интервале составов по сравнению с другими образцами.

Использование МЭБ такой структуры позволит обеспечить эффективную (высокий КПД, большая удельная мощность и пр.) работу топливных элементов в широком диапазоне условий их применения.

\section{Конфликт интересов}

Авторы заявляют, что у них нет конфликта интересов.

\section{Список литературы}

[1] D. Niblett, V. Niasar, S. Holmes. J. Electrochem. Society, 167 (1), 013520 (2020). DOI: 10.1149/2.0202001JES

[2] Sh. Shi, X. Guo, B. Chen, Z. Sun. J. Engineer. Fibers and Fabrics, 14, 1 (2019). DOI: 10.1177/1558925019896438

[3] S. Kattamanchi, K. Palakurthi, P. Haridoss. Energy Technol., 8, 2000119 (2020). DOI: 10.1002/ente.202000119

[4] B. Chi, Y.K. Ye, X.Y.Lu, S.J. Jiang, L. Du, J.H.Zeng, J.W. Ren, S.J. Liao. J. Power Sources, 443, 227284 (2019). DOI: 10.1016/j.jpowsour.2019.227284

[5] Ch. Luo, H. Xie, Q. Wang, G. Luo, Ch. Liu. Nanostructured Carbon Mater., 2015, 1(2015). DOI: 10.1155/2015/560392

[6] R. Wlodarczyk. Mater. Sci. Applicat., 10, 643 (2019). DOI: $10.4236 / \mathrm{msa} .2019 .1010046$

[7] А.А. Нечитайлов, Н.В. Глебова, А.О. Краснова. ЖCX, 60 (9), 1567 (2019). DOI: 10.26902/JSC_id46206 [A.A. Nechitailov, N.V. Glebova, A.O. Krasnova. J. Structur. Chem., 60 (9), 1507 (2019). DOI: $10.1134 / \mathrm{S} 0022476619090166]$

[8] Электроннй ресурс. Режим доступа: URL:https:/www.fuelcellstore.com/spec-sheets/vulcan-xc72-spec-sheet.pdf

[9] Н.В. Глебова, А.А. Нечитайлов. Перспективные материалы, спец. выпуск „Функциональные наноматериалы и высокочистые вещества“, 9, 71 (2010).

[10] M. Uchida, Y. Aoyama, M. Tanabe, N. Yanagihara, N. Eda, A. Ohta. J. Electrochem. Soc., 142, 2572 (1995)
[11] J. McBreen, H. Olender, S. Srinivasan, K. Kordesch. J. Appl. Electrochem., 11, 787 (1981)

[12] D. Pantea, H. Darmstadt, S. Kaliaguine, L. Summchen, C. Roy. Carbon, 39, 1147 (2001). DOI: $10.1016 / \mathrm{S} 0008-6223(00) 00239-6$

[13] E. Antolini. Appl. Catalys. B: Environmental, 88, 1 (2009). DOI: 10.1016/j.apcatb.2008.09.030

[14] Электронный ресурс. Режим доступа: URL: http://www.nanotc.ru/producrions/87-cnm-taunit

[15] А.О. Краснова, Н.В. Глебова, А.А. Нечитайлов. ЖПХ, 89 (6), 756 (2016). DOI: 10.1134/S1070427216060112 [A.O. Krasnova, N.V. Glebova, A.A. Nechitailov. Rus. J. Appl. Chem., 89 (6), 916 (2016). DOI: $10.1134 / \mathrm{S} 1070427216060112]$

[16] В.И. Мазин, Е.В. Мазин. Способ получения пористого углеродного материала на основе высокорасщепленного грабита. Патент РФ № 2581382. Приоритет от 22.04.2014. Опубликовано 20.04.2016 в Бюл. № 11.

[17] Н.В. Глебова, А.О. Краснова, А.А. Нечитайлов. ЖПХ, 91 (8), 1111 (2018). DOI: 10.1134/S1070427218080037 [N.V. Glebova, A.O. Krasnova, A.A. Nechitailov. Rus. J. Appl. Chem., 91 (8), 1262 (2018). DOI: $10.1134 / \mathrm{S} 1070427218080037]$

[18] S. Litster, G. McLean. J. Power Sources, 130, 61 (2004). DOI: 10.1016/j.jpowsour.2003.12.055

[19] Д.А. Андроников, Н.К. Зеленина, Е.Е. Терукова, А.А. Томасов. Способ активации мембранно-электродного блока. Патент РФ № 2487442. Приоритет от 28.02.2012. Опубликовано 10.07.2013 в Бюл. № 19.

[20] Электронный ресурс. Режим доступ: URL: http://fuelcell.com/product/fc-05-02/

[21] F. Beck, M. Dolata, E. Grivei, N. Probst. J. Appl. Electrochem., 31, 845 (2001).

[22] В.Л. Хейфец, Д.К. Авдеев, Л.С. Рейшахрит. Практикум по теоретической электрохимии. (Изд-во Ленинградского ун-та, Л., 1954), с. 50.

[23] J. Bett, K. Kinoshita, K. Routsis, P. Stonehart. J. Catalys., 29 (1), 160 (1973). DOI: 10.1016/0021-9517(73)90214-5 